\title{
Correction to "Cognitive Effects of MDMA in Laboratory Animals: A Systematic Review Focusing on Dose"
}

In the above article [Pantoni MM and Anagnostaras SG (2019) Pharmacol Rev, 71: 413-449; DOI: https://doi.org/10.1124/pr.118.017087], the evidence of MDMAinduced cognitive enhancements at doses of less than $3 \mathrm{mg} / \mathrm{kg}$ was accidentally omitted from Fig. 11A. The corrected Fig. 11 is provided below. The PDF and HTML versions of the article have been corrected.

A

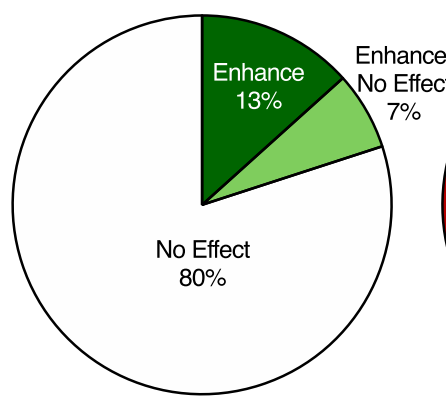

$<3 \mathrm{mg} / \mathrm{kg}$ MDMA
B

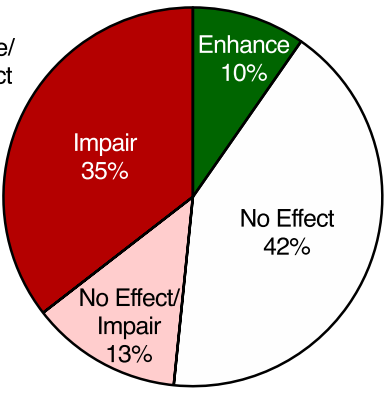

3-6 mg/kg MDMA

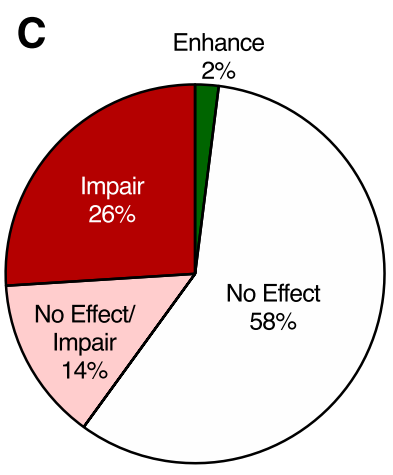

7.5-10 mg/kg MDMA

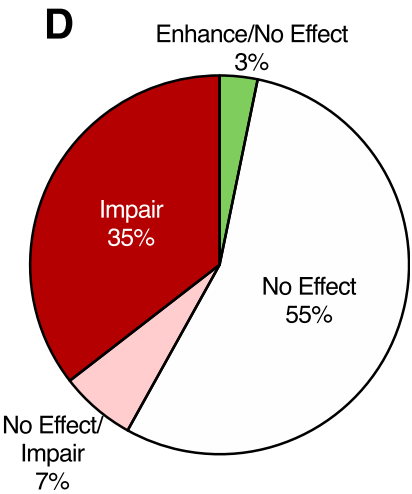

15-30 mg/kg MDMA

The authors apologize for any inconvenience caused by this error. 